\title{
Digestion in sea urchin larvae impaired under ocean acidification
}

\author{
Meike Stumpp ${ }^{1,2,3 \dagger}$, Marian Hu ${ }^{1,2,3 \dagger}$, Isabel Casties ${ }^{1}$, Reinhard Saborowski ${ }^{4}$, Markus Bleich ${ }^{2}$, \\ Frank Melzner ${ }^{3}$ and Sam Dupont ${ }^{1 \star}$
}

\begin{abstract}
Larval stages are considered as the weakest link when a species is exposed to challenging environmental changes ${ }^{1,2}$. Reduced rates of growth and development in larval stages of calcifying invertebrates in response to ocean acidification might be caused by energetic limitations ${ }^{3}$. So far no information exists on how ocean acidification affects digestive processes in marine larval stages. Here we reveal alkaline ( $\sim$ pH 9.5) conditions in the stomach of sea urchin larvae. Larvae exposed to decreased seawater $\mathrm{pH}$ suffer from a drop in gastric $\mathrm{pH}$, which directly translates into decreased digestive efficiencies and triggers compensatory feeding. These results suggest that larval digestion represents a critical process in the context of ocean acidification, which has been overlooked so far.
\end{abstract}

Ocean acidification as it is projected for the next century can affect vital functions of marine organisms. Larval stages are often particularly sensitive to ocean acidification. Decreased survival of larvae can directly affect population stability and could lead to decreased ecosystem integrity. As observed in several species, disturbances of extra- or intracellular acid-base homeostasis were correlated with energy budget reallocation and decreased scope for somatic growth and development ${ }^{4,5}$. However, little attention has been placed on whether digestive processes are impacted by decreased seawater $\mathrm{pH}$, particularly in larval stages of marine invertebrates.

According to the preferred sources of nutrients and the necessary catabolic enzymes, digestive systems with distinct $\mathrm{pH}$ environments have evolved. For example, stomachs of most vertebrates operate at an acidic $\mathrm{pH}$ of $\sim 2$, corresponding to maximum activity of most gastric enzymes at low $\mathrm{pH}$ (ref. 6). On the other hand, the midgut of larvae of several insect species operates at a strongly alkaline $\mathrm{pH}$ of $\sim 11$ for the benefit of digestive enzymes (proteases, phosphatases) with a highly alkaline $\mathrm{pH}$ optimum ${ }^{7}$. To maintain high enzyme activities, digestive system $\mathrm{pH}$ is regulated by active ion transport processes through the net export or import of acid equivalents ${ }^{8}$.

Here we investigated the effects of seawater acidification on digestive processes in green sea urchin pluteus larvae (Strongylocentrotus droebachiensis), which are keystone species in temperate and subpolar kelp ecosystems ${ }^{9}$. Owing to the fact that pluteus larvae cannot regulate the extracellular $\mathrm{pH}$ in their primary body cavity ${ }^{3}$ the larval digestive system is directly exposed to changes in seawater $\mathrm{pH}$. We reasoned that changes in seawater $\mathrm{pH}$ will directly influence the larval physiology by reducing stomach $\mathrm{pH}$, digestive enzyme activity, and thus food assimilation and/or by challenging the acid-base regulatory machinery responsible for stomach $\mathrm{pH}$ maintenance. In terms of larval energy budgets, such challenges may be a critical reason for the reported reductions in growth and development of echinoid larvae in response to acidified sea water.

Using ion-selective micro-electrodes we found that the stomach $\mathrm{pH}$ of sea urchin pluteus larvae is alkaline, steadily increasing during ontogenesis from $\mathrm{pH} 8.9$ in 5 day post-fertilization (dpf) to pH 9.6 in 9 dpf larvae (Figs 1a-d and 2a). Alkaline conditions in the digestive tract of herbivorous insects have been demonstrated to favour the solubility of plant proteins as well as the dissociation of phenol-protein complexes ${ }^{10,11}$. Furthermore, algal and higher plant chloroplasts are more efficiently digested at higher $\mathrm{pH}$ than at acidic or neutral $\mathrm{pH}$ (refs 12,13). Thus, alkaline conditions increase the ability to digest and dissolve dietary protein. This may also be advantageous to improve the utilization of algal proteins in an often nitrogen-limited trophic environment for most marine herbivores ${ }^{14,15}$.

Chronic exposure to $\mathrm{pH} 7.7$ or $\mathrm{pH} 7.4$ sea water decreased stomach $\mathrm{pH}$ by 0.3 or 0.5 units indicating gastric alkalinity could not be maintained. (Fig. 1b,c). This effect was still evident when gastric $\mathrm{pH}$ values were corrected for developmental stage, demonstrating that gastric $\mathrm{pH}$ reduction can be attributed to ocean acidification rather than to developmental delay (Fig. 1d). Acute exposure (15-20 min) to acidified conditions ( $\mathrm{pH}$ 7.3) could not change gastric pH (Supplementary Fig. S2C). The energetic consequence of the gastric $\mathrm{pH}$ reduction becomes even clearer when converting the $\mathrm{pH}$ gradients between stomach lumen and primary body cavity/sea water into proton concentrations. Under control conditions (sea water, $\mathrm{pH}$ 8.1) larvae maintain a $\mathrm{H}^{+}$concentration gradient of $7.9 \mathrm{nmoll}^{-1}$, whereas under acidified conditions (sea water, $\mathrm{pH} 7.4$ ), this gradient increases to $39.8 \mathrm{nmoll}^{-1}$. These findings indicate that during chronic exposure to low $\mathrm{pH}$, pluteus larvae are able to stabilize stomach $\mathrm{pH}$ at higher levels than expected by the observed decreases in seawater $\mathrm{pH}$. We thus suggest the presence of well-developed ion-transporting gastric epithelia.

Using whole-mount immunostainings we could demonstrate that an antibody against avian $\mathrm{Na}^{+} / \mathrm{K}^{+}$-ATPase (NKA) detects a protein at the luminal surface and apical cytoplasm of stomach and intestinal cells (Fig. 1e). NKA is an important enzyme in ion-regulatory epithelia of many marine organisms ${ }^{16}$. It creates an electrochemical gradient that can energize other secondary active transporters relevant for acid-base regulation ${ }^{17}$. Although it is tempting to speculate that NKA is mainly involved in gastric alkalization, this enzyme also contributes to nutrient and amino acid uptake in sea urchin larvae ${ }^{18}$. For example, the uptake of

${ }^{1}$ Department of Biological and Environmental Sciences, University of Gothenburg, The Sven Lovén Centre for Marine Sciences, Kristineberg 45178 Fiskebäckskil, Sweden, ${ }^{2}$ Institute of Physiology, Christian Albrechts University Kiel, 24098 Kiel, Germany, ${ }^{3}$ Helmholtz Centre for Ocean Research Kiel (GEOMAR), 24105 Kiel, Germany, ${ }^{4}$ Alfred Wegener Institute, Helmholtz Centre for Polar and Marine Research, Functional Ecology, 27515 Bremerhaven, Germany. ${ }^{\dagger}$ These authors contributed equally to this work. ${ }^{\star} e-m a i l: s a m . d u p o n t @ b i o e n v . g u . s e$ 
a

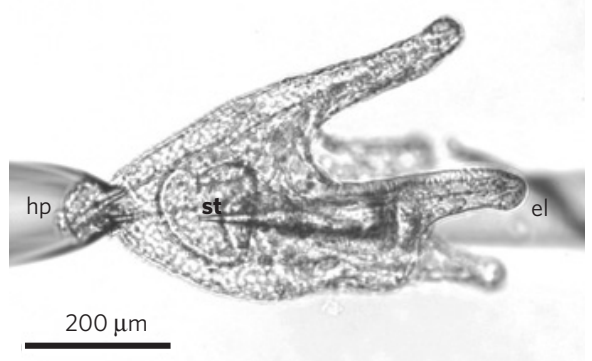

C

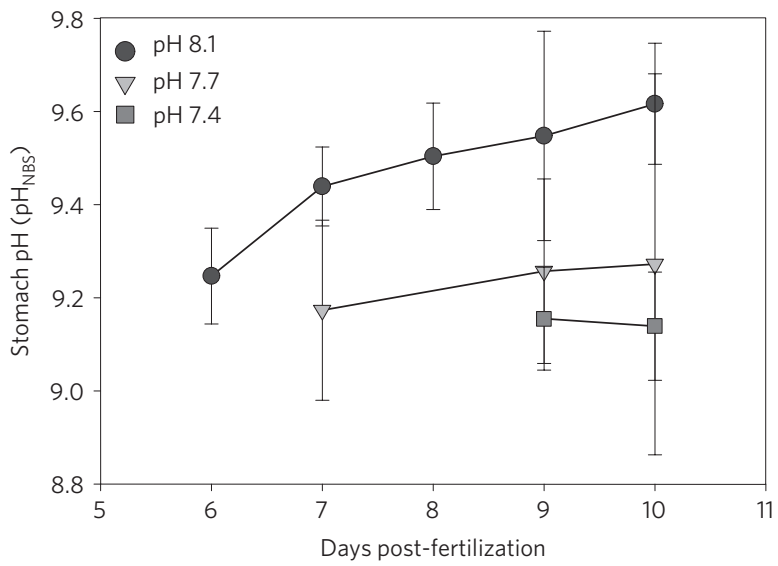

e

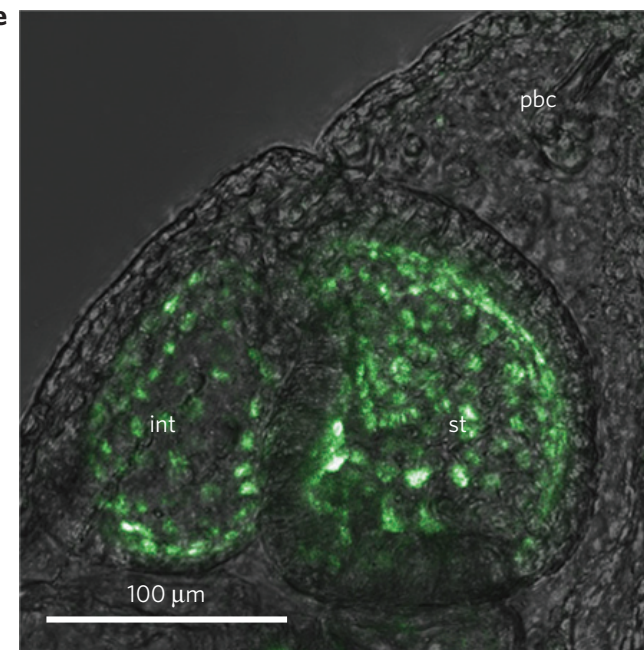

b

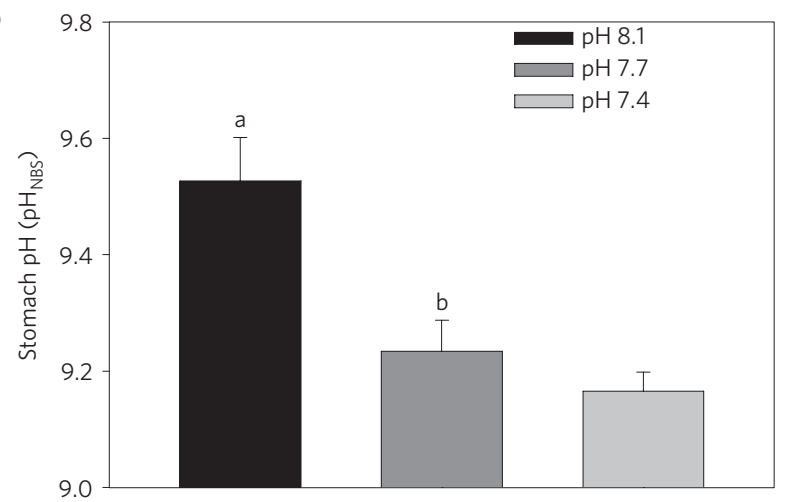

d

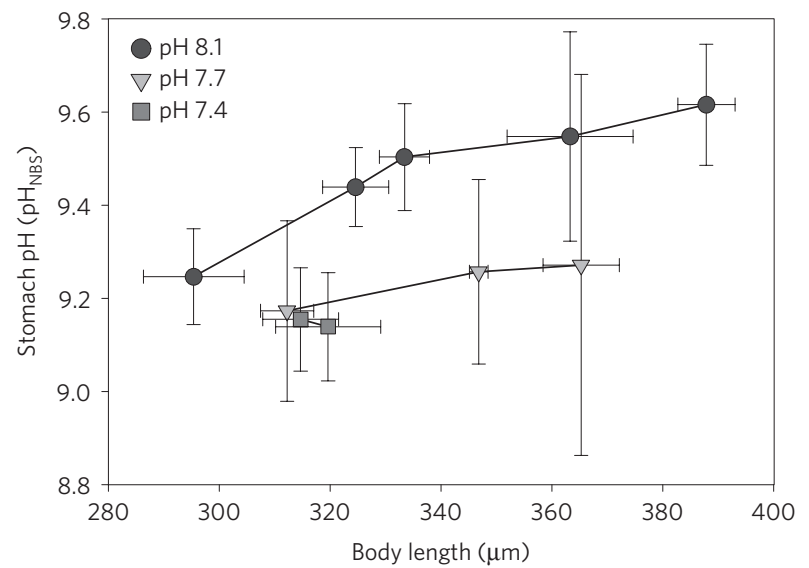

f

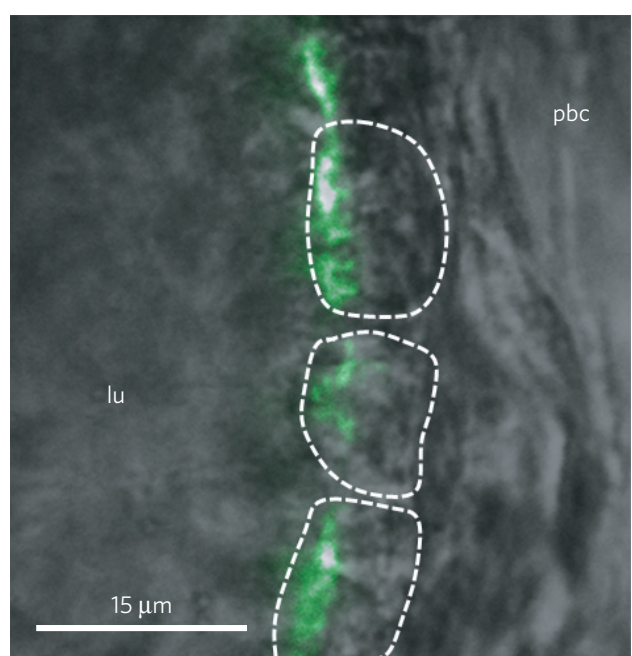

Figure 1 | Effects of acidified sea water on gastric pH homeostasis. a, In vivo measurements of larval stomach pH using ion-selective micro-electrodes.

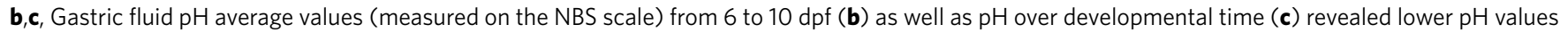
in larvae reared in decreased $\mathrm{pH}$. Letters denote significant differences among treatments. Values are presented as mean $\pm \mathrm{s}$.d. ( $n=3$ ). Within this time

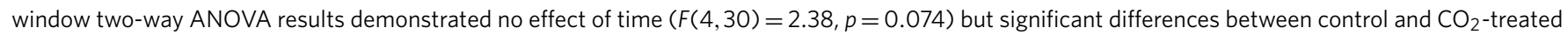
larvae $(F(2.30)=12.86, p<0.001)$. d, The reduced gastric $\mathrm{pH}$ was still evident when $\mathrm{pH}$ values were corrected for developmental delay.

e, Immunohistochemical detection of $\mathrm{Na}^{+} / \mathrm{K}^{+}$-ATPase (NKA)-rich cells in the stomach and intestinal epithelium. $\mathbf{f}$, NKA is localized in luminal membranes. The dashed lines indicate the location of cells. For controls, see Supplementary Fig. S4. Microelectrode (el), stomach (st), holding pipette (hp), intestine (int), primary body cavity (pbc), lumen (lu).

neutral amino acids in pluteus larvae is $\mathrm{Na}^{+}$-dependent and in vivo NKA activities increase in the presence of alanine in sea water ${ }^{19,20}$.

The importance of NKA in sea urchin pluteus larvae is reflected in high (up to $77 \%$ of the total metabolic rate) metabolic requirements that can be attributed to energetic demands of this enzyme ${ }^{20}$. Increased expression of the NKA $\alpha$-subunit in larvae of the purple sea urchin (Strongylocentrotus purpuratus) indicated a higher demand of this enzyme under 
a

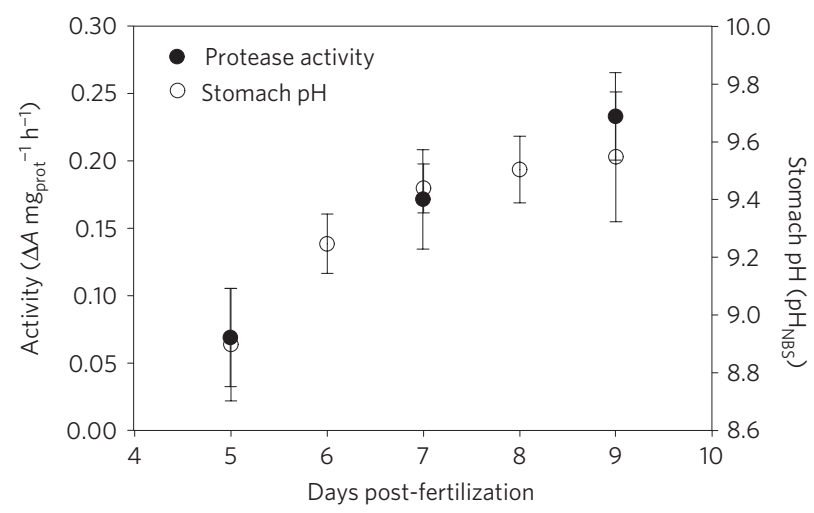

b

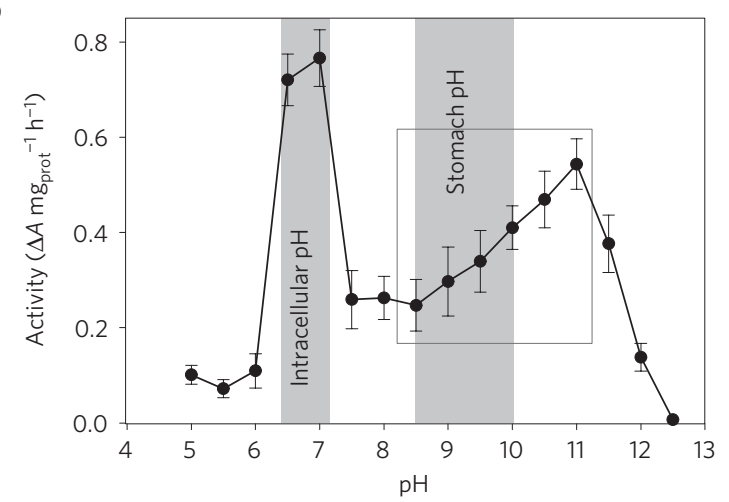

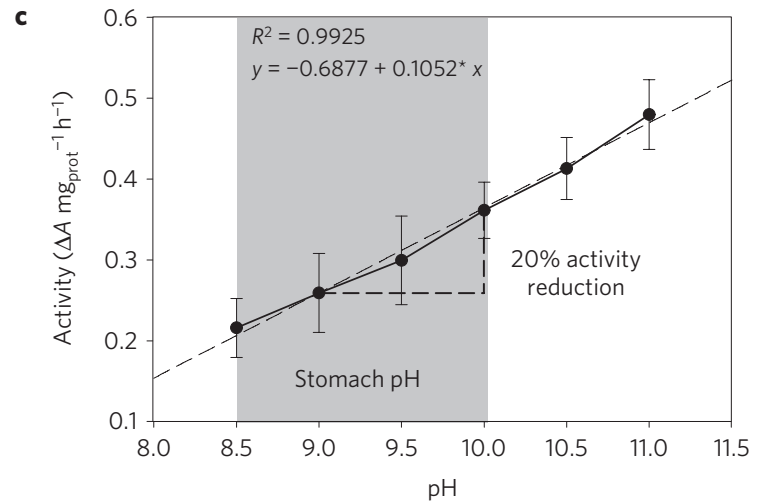

Figure 2 | Characterization of proteases in sea urchin larvae raised at pH 8.1. a, During early embryonic development total protease activity increased accompanied with an alkalization of gastric fluids. $\mathbf{b}$, Proteases have one $\mathrm{pH}$ optimum at 6.5-7 and a second optimum at pH 11. c, The enzyme activity increased linearly between $\mathrm{pH} 8.5$ and $\mathrm{pH} 11$ by $20 \%$ of activity per $\mathrm{pH}$ unit. Values are presented as mean \pm s.d. $(n=3)$.

acidified conditions ${ }^{21}$. The upregulation of NKA in this species is paralleled by an increase in metabolic rate, indicating a higher energy demand in response to $\mathrm{CO}_{2}$-mediated seawater acidification $^{5}$. Thus, additional costs for acid-base regulation to maintain alkaline digestive conditions or other energyconsuming compensatory digestive functions (for example, increased nutrient absorption) could significantly affect the organism's energy budget.

Proteolytic enzymes are important compounds of the digestive machinery of pluteus larvae to use dietary proteins and, thus, to meet nutritional nitrogen and amino acid requirements. Proteolytic activity as well as gastric $\mathrm{pH}$ increased in sea urchin larvae during ontogenesis (Fig. 2a), indicating a steadily rising digestive capacity.

Using in vitro enzyme assays, we found that sea urchin proteases are characterized by two $\mathrm{pH}$-dependent maxima. The first maximum lies in a narrow $\mathrm{pH}$ range between $\mathrm{pH} 6.5$ and $\mathrm{pH} 7$ (Fig. 2b) and may be attributed to intracellular proteases that play an important role in specific post-translational processing, cell cycle, apoptosis mechanisms and digestive processes at intracellular $\mathrm{pH}$ conditions $\mathrm{s}^{22,23}$. For example, type II cells of the pluteus larval stomach epithelium were described to phagocytose and digest whole algal cells ${ }^{24}$. This suggests the presence of intracellular digestion mechanisms, which specifically target phagocytosed algal cells. The second and wider maximum between $\mathrm{pH} 8.5$ and $\mathrm{pH} 12$ (Fig. 2b) can be attributed to alkaline proteases that have their maximum activity at $\mathrm{pH} 11$. A very similar $\mathrm{pH}$-dependent enzyme activity pattern with a peak in maximum activity between $\mathrm{pH} 8$ and 10 was found for alkaline phosphatase in pluteus larvae of the sea urchin (S. droebachiensis $)^{25}$.
Alkaline phosphatase also is a very abundant enzyme in the digestive tract of Stronglyocentrotus sea urchin larvae, particularly in stomach epithelia ${ }^{26}$. We found proteolytic activity to increase linearly by $20 \%$ per pH unit between pH 8.5 and pH 11 (Fig. 2c). Hence, a shift towards more acidic conditions in the stomach as we observed in the $\mathrm{CO}_{2}$-treated larvae would reduce proteolytic activity. In sea urchin larvae exposed to acidified seawater of $\mathrm{pH} 7.5$, this reduction would decrease protease activity by about $8 \%$. Similarly, strong reductions (up to $40 \%$ ) in alkaline phosphatase activity can be expected ${ }^{25}$. The degradation rate of ingested Rhodomonas cells, measured as chlorophyll $a$-dependent fluorescence intensity (Fig. 3a), was significantly (by 33\%) reduced under acidified conditions (Fig. 3b), indicating a reduced digestive potential.

Larvae exposed to low $\mathrm{pH}$ ( $\mathrm{pH}$ 7.2) had a delayed development and reduced somatic growth, which was also reflected by a delayed increase in proteolytic activity (Fig. 4a). However, in vitro determinations of maximum proteolytic activities (measured at the optimum $\mathrm{pH}$ of 11) at a body length of $350 \mu \mathrm{m}$ (Fig. 4b) or at 10 $\mathrm{dpf}$ (Fig. 4b) did not result in differences between control and low$\mathrm{pH}$-treated larvae, suggesting that a loss in maximum proteolytic activity due to a shift in gastric $\mathrm{pH}$ is probably not compensated by increased enzyme synthesis. Nevertheless, at ecologically realistic

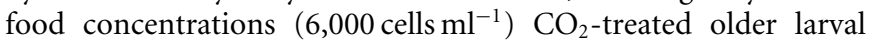
stages ( $>400 \mu \mathrm{m}$ body length) seemed to compensate for lower digestive capacities by feeding at higher rates $(+11-33 \%$, Fig. $4 c, d)$. Our results suggest that decreased digestive efficiency seems to lead to compensatory feeding in sea urchin larvae. Compensatory feeding in response to lowered food quality and nutrient availability has been documented for terrestrial and marine invertebrates ${ }^{27,28}$. 

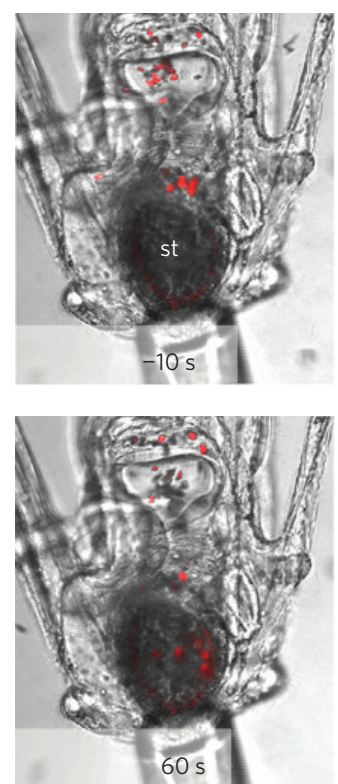
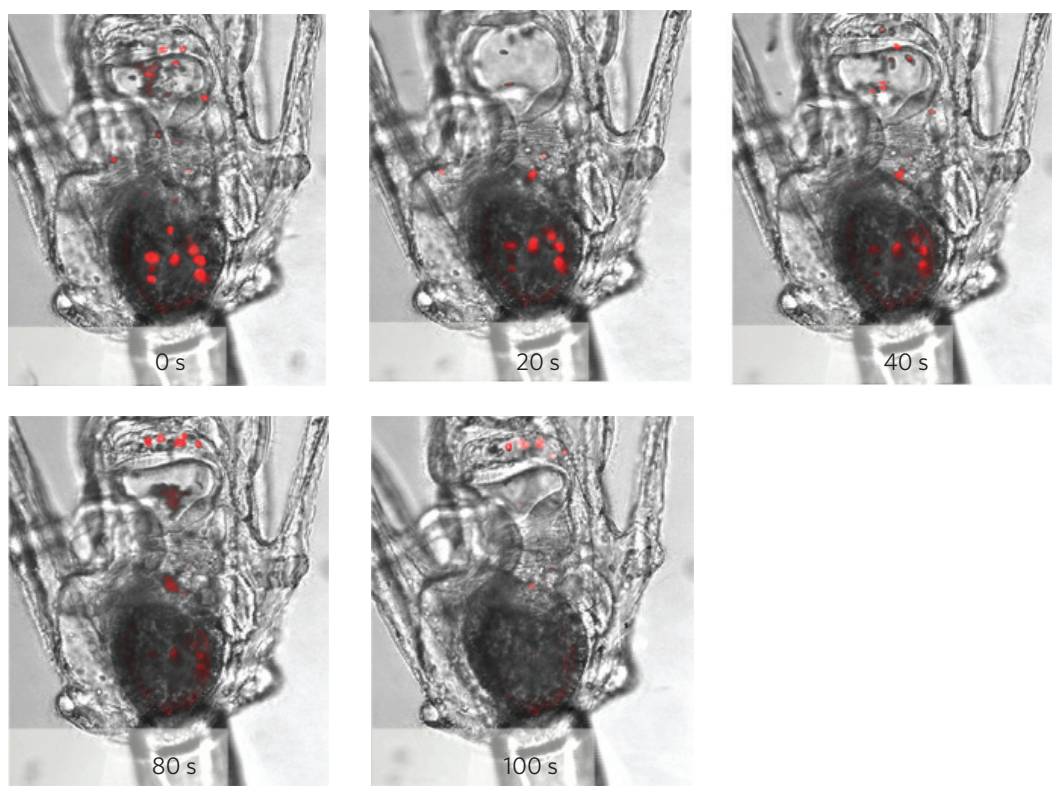

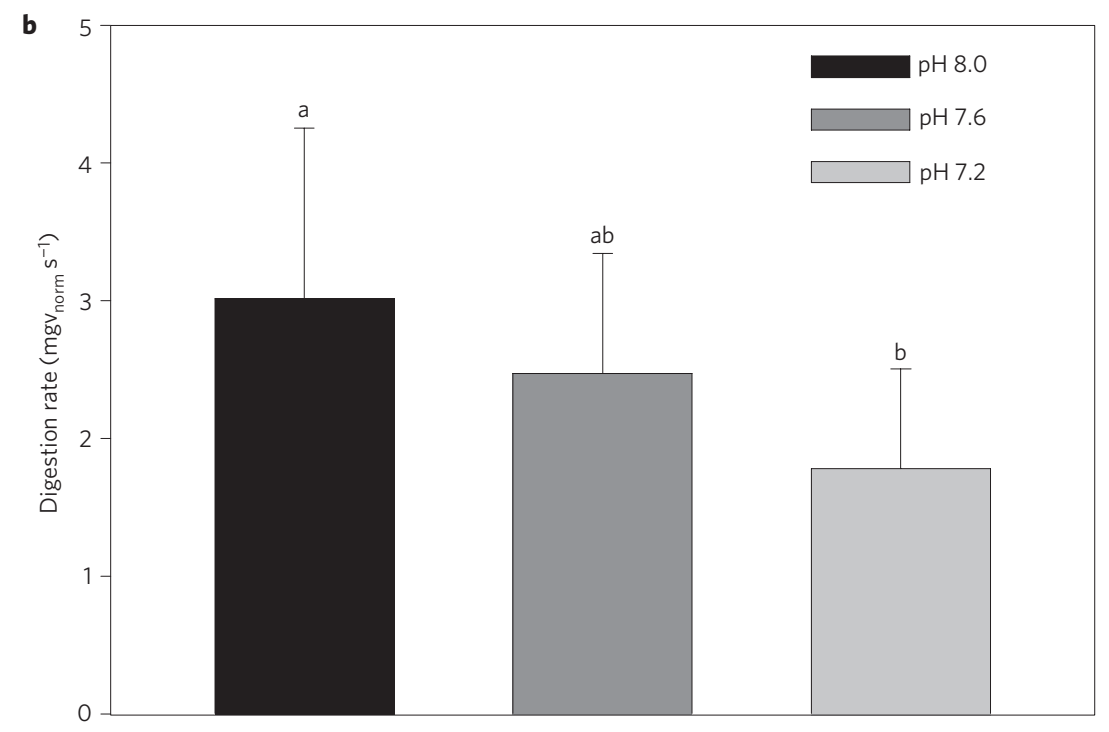

Figure 3 | In vivo digestion of sea urchin pluteus larvae exposed to different pH treatments. In vivo digestion rates of Rhodomonas cells were measured using confocal microscopy and are expressed as change in mean greyscale values (mgv) per time (Supplementary Fig. S5). a, Image series illustrating the in vivo digestion of Rhodomonas cells in a larva raised at pH 8.1. b. Digestion efficiency decreases in low-pH-treated larvae. Values are presented as mean \pm s.d. $(n=8-9)$. For this experiment larvae between 8 and $16 \mathrm{dpf}$, corresponding to a body length range of $230-440 \mu \mathrm{m}$, were used. Different letters denote statistical differences among treatments (one-way ANOVA, $F(2,23)=3.559, p=0.045$ ); stomach (st).

However, compensatory feeding in response to decreased digestive abilities was not previously documented for larvae of marine invertebrate species. In this context, one has to keep in mind that the particle-feeding capacity in echinoid larvae is directly related to their morphological appearance, for example, ciliary band length on the larval $\mathrm{arms}^{29}$. As the allometric proportions of echinoid larvae are not changing in response to elevated $p_{\mathrm{CO}_{2}}$ (ref. 5), larvae from all treatments have the same maximum feeding potential and are thus limited in their capacity to compensate digestive inefficiency by increased feeding rates.

Elevated energetic costs for acid-base regulation to maintain calcification rates have been previously discussed as a critical factor for reduced development and growth in echinoid larvae ${ }^{3}$. The present work demonstrates that besides calcification alkalization of gastric $\mathrm{pH}$ constitutes another potential energy sink in sea urchin larvae facing ocean acidification. In addition, the shift of gastric $\mathrm{pH}$ towards more acidic conditions during ocean acidification decreases digestive efficiencies. Despite potential compensatory feeding mechanisms it is likely that the larval energy budget might be significantly affected by impaired food utilization accompanied with increased costs for gastric alkalization under acidified conditions.

Overall, the concept of energy limitation and reallocation in response to ocean acidification can provide an integrative approach for understanding the common principles of vulnerability of larval stages of key marine species. This will allow for a better understanding of the influence of climate change on recruitment success of marine keystone species and the ecosystems they shape. 


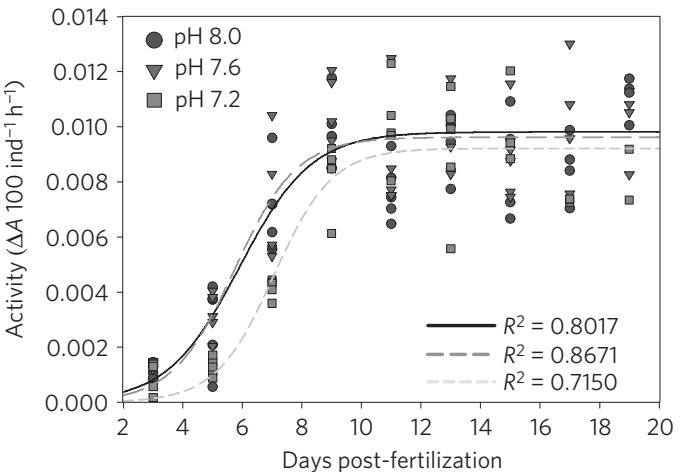

b

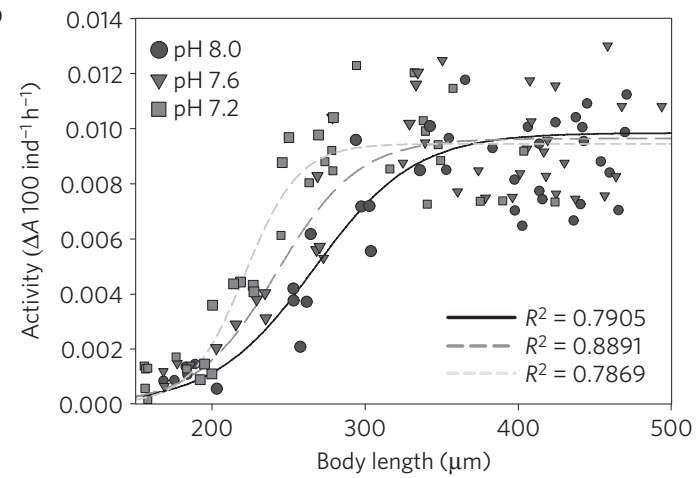

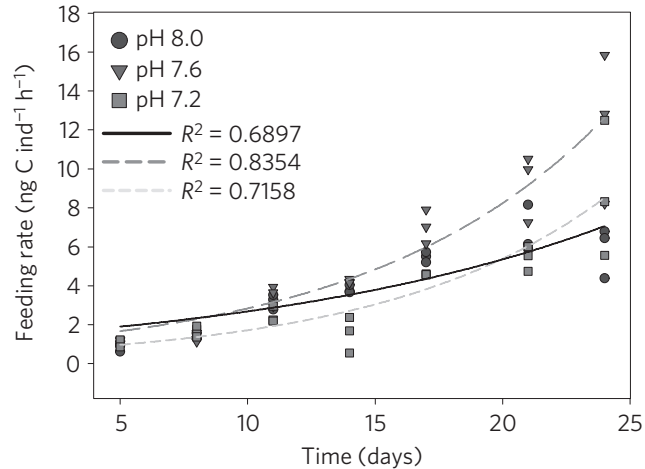

d

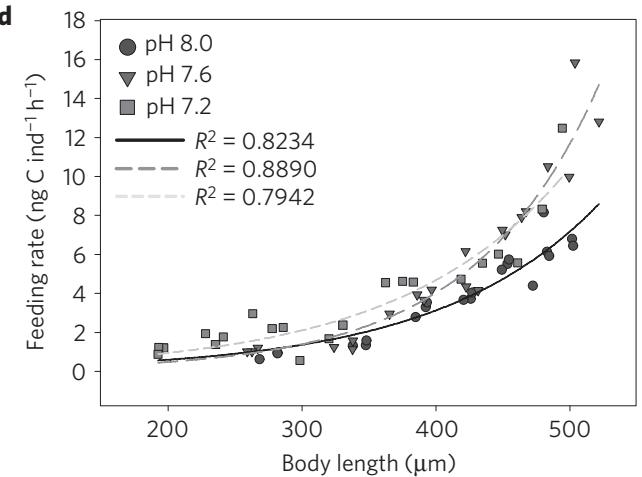

Figure 4 | Comparison of total protease activity in larvae cultured under different pH conditions. a, Larvae raised at pH 7.2 showed a delayed increase in protease activity compared with larvae raised at $\mathrm{pH} 8.0$ and 7.6, but reached and maintain the same maximum activity after 11 days. b, Protease activity corrected to larval size. Total protease activity was fitted by a sigmoidal curve $\left(y=a /\left(1+e^{(-x-x 0) / b)}\right)\right.$ with time and size as variables. $\mathbf{c}, \mathbf{d}$, Feeding rates as a function of time $(\mathbf{c})$ and size $(\mathbf{d})$. Feeding rates were fitted by an exponential function $\left(y=a * \mathrm{e}^{(b * \mathrm{x})}\right)$ and $\mathrm{pH}$ had a significant effect on feeding rate (analysis of co-variance, $F=3.54, p=0.029$ with time as a co-variable and $F=14.90, p<0.0001$ with body length as a co-variable). For statistical information on regression curves see Supplementary Table S2.

\section{Methods}

pH perturbation experiments. $\mathrm{pH}$ perturbation experiments for studies on the gastric $\mathrm{pH}$ in sea urchin larvae (S. droebachiensis) were carried out in 2011 at GEOMAR and CAU Kiel (Germany; exp 1; duration: 10 days). For enzyme assays and feeding experiments another $\mathrm{pH}$ perturbation experiment was conducted in spring 2012 at the Sven Lovén Centre for Marine Sciences (Kristineberg, Sweden; $\exp 2$; duration: 24 days). Adult $S$. droebachiensis were collected in winter 2011/2012 in the Oslo Fjord (Dröbak, Norway; same population used in a previous study ${ }^{3}$ ) by scuba divers. Fertilization and $\mathrm{CO}_{2}$ perturbation experiments were conducted as previously described ${ }^{3,5}$ (also see Supplementary Information for more information).

Measurement of gastric $\mathrm{H}^{+}$concentrations. Ion-selective electrode measurements were performed as described previously ${ }^{3}$ to measure $\mathrm{H}^{+}$concentrations in the stomach of sea urchin larvae. The linear regression between voltage output and $\log \left[\mathrm{H}^{+}\right]$values of artificial seawater solutions $(\mathrm{pH} 6,7,8$ and 9) yielded a Nernstian slope of $49.8 \pm 2.3 \mathrm{mV}(n=12)$ for $1 \mathrm{pH}$ unit. The ion-selective probe was introduced into the stomach through the oesophagus (Fig. 1a). pH recordings were performed on pluteus larvae (5-10 dpf; pre-feeding day 5 omitted in Fig. 1) reared under control and hypercapnic conditions to address the effects of chronically elevated seawater $p_{\mathrm{CO}_{2}}$ (meaning continuous exposure starting after the first cell division) on gastric $\mathrm{pH}$ homeostasis.

Immunohistochemical staining. Whole-mount immunocytochemistry was performed as previously described ${ }^{5}$. Samples were incubated with a monoclonal antibody IgGa5 raised against the avian $\alpha$ subunit of NKA (Developmental Studies Hybridoma Bank, University of Iowa). After being rinsed with PBS, samples were further incubated in goat anti-rabbit IgG Alexa-Fluor 488 (dilution 1:100). Samples were examined with a Leica confocal microscope (SP5).

Protease activity measurements. Total protease activity was determined using azo-casein sodium salt (Sigma Aldrich) as the substrate. The assays were carried out with $2 \mu \mathrm{l}$ of crude enzyme extracts that were added to $20 \mu \mathrm{l}$ of universal buffer $^{30}$ adjusted to the required $\mathrm{pH}$. After five minutes of pre-incubation, $5 \mu \mathrm{l}$ of substrate $\left(1 \% \mathrm{w} / \mathrm{v}\right.$ in buffer) was added and incubated for $20 \mathrm{~h}$ at $25^{\circ} \mathrm{C}$. The reaction was stopped by the addition of $50 \mu$ lof ice-cold trichloroacetic acid solution $(8 \% \mathrm{w} / \mathrm{v}$ in distilled water). The samples were centrifuged at $15,000 \mathrm{~g}$ for $15 \mathrm{~min}$ at $4^{\circ} \mathrm{C}$. The absorbance $(A)$ of the supernatant was read at $366 \mathrm{~nm}$ on a NanoDrop 1000 (Thermo Scientific) spectrophotometer. The absorbance of controls, to which crude extracts were added after stopping the reaction with trichloroacetic acid, was subtracted from the absorbance of the assay. Protein concentrations of the crude extracts were determined with a commercial protein assay kit (Pierce, Thermo Scientific) and bovine serum albumin as the standard. Enzyme activities are expressed as change in absorbance per milligram of protein and per hour $\left(\triangle A \mathrm{mg}_{\text {prot }}^{-1} \mathrm{~h}^{-1}\right)$.

In vivo digestion rates. Larvae were kept in position using a holding pipette for $5 \mathrm{~min}$ before the start of the measurements inside the perfusion chamber (set to respective culture $\mathrm{pH}$, that is, $8.0,7.6,7.2$ ) on a Leica confocal microscope (SP5). Three min after the start of the measurements, Rhodomonas cells were added to the

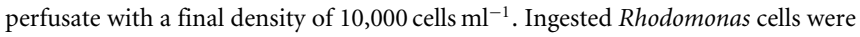
excited with $488 \mathrm{~nm}$ and the emission signal was recorded between 670 and $700 \mathrm{~nm}$. Bleaching of cells was not observed (Supplementary Fig. S3 upper panel) and the settings resulted in a linear decrease in fluorescence intensity when algae were digested (Supplementary Fig. S5). Images were acquired every $10 \mathrm{~s}$, and analysed using the open source program Image J.

Determination of feeding rates. To assess the impact of elevated seawater $p_{\mathrm{CO}_{2}}$ on feeding performance, feeding rates were determined as described previously ${ }^{5}$. Feeding rate was estimated as clearance rate by measuring the algal concentration (delta cells $\mathrm{l}^{-1}$ ) at the end of the incubation $(24 \mathrm{~h})$ in control and experimental bottles with decreased $\mathrm{pH}$ levels. The rates were corrected for mortality and presented as rates per surviving animal in nanograms of carbon per individual per hour $\left(\right.$ ng C ind $\left.{ }^{-1} h^{-1}\right)$.

Statistical analysis. Statistical analyses were performed using Sigma Stat 3.0 (Systat) and SAS software. Statistical differences between ion-selective electrode measurements and in vivo digestion rates were analysed by two-way and one-way analysis of variance (ANOVA) followed by Tukey's post-hoc test. Simple linear and logarithmic regression models were used to test the relationship type between the variables. Analysis of co-variance was used to test for $\mathrm{pH}$ effects on the growth and feeding rates using time post-fertilization (TPF) or body length as a co-variable. When logarithmic relationships were calculated, TPF and body length were logarithm transformed. Sigmoidal (three parameter) regression models were used 
to fit the TPF versus protease activities and growth versus protease activities. Data sets were normally distributed (Kolmogorov-Smirnov test). Equal variance was tested using the Levene median test. The significance level was set to $p<0.05$.

Received 31 May 2013; accepted 16 September 2013; published online 20 October 2013

\section{References}

1. Kurihara, $\mathrm{H}$. Effects of $\mathrm{CO}_{2}$-driven ocean acidification on the early developmental stages of invertebrates. Mar. Ecol. Prog. Ser. 373, 275-284 (2008).

2. Dupont, S., Ortega-Martinez, O. \& Thorndyke, M. Impact of near-future ocean acidification on echinoderms. Ecotoxicology 19, 449-462 (2010).

3. Stumpp, M. et al. Acidified seawater impacts sea urchin larvae $\mathrm{pH}$ regulatory systems relevant for calcification. Proc. Natl Acad. Sci. USA 109, 18192-18197 (2012).

4. Stumpp, M., Trübenbach, K., Brennecke, D., Hu, M. Y. \& Melzner, F. Resource allocation and extracellular acid-base status in the sea urchin Strongylocentrotus droebachiensis in response to $\mathrm{CO}_{2}$ induced seawater acidification. Aquat. Toxicol. 110-111, 194-207 (2012).

5. Stumpp, M., Wren, J., Melzner, F., Thorndyke, M. C. \& Dupont, S. $\mathrm{CO}_{2}$ induced seawater acidification impacts sea urchin larval development I: Elevated metabolic rates decrease scope for growth and induce developmental delay. Comp. Biochem. Physiol. A 160, 320-330 (2011).

6. Piper, D. W. \& Fenton, B. H. pH stability and activity curves of pepsin with special reference to their clinical importance. Gut 6, 506-508 (1965).

7. Sharma, B. R., Martin, M. M. \& Shafer, J. A. Alkaline proteases from the gut fluids of detritus-feeding larvae of the crane fly, Tipula abdominalis (Say) (Diptera, Tipulidae). Insect Biochem. 14, 37-44 (1984).

8. Sachs, G. in Physiology of The Gastrointestinal Tract (ed. Johnson, L. R.) 1119-1138 (Raven, 1994).

9. Sivertsen, K. Geographic and environmental factors affecting the distribution of kelp beds and barren grounds and changes in biota associated with kelp reduction at sites along the Norwegian coast. Can. J. Fish Aquat. Sci. 54, 2872-2887 (1997).

10. Berenbaum, M. Adaptive significance of midgut $\mathrm{pH}$ in larval Lepidoptera. Am. Nat. 115, 138-146 (1980).

11. Felton, G. W. \& Duffey, S. S. Reassessment of the role of gut alkalinity and detergency in insect herbivory. J. Chem. Ecol. 17, 1821-1836 (1991).

12. Stahmann, M. A. Plant proteins. Annu. Rev. Plant Physiol. 14, 137-158 (1963)

13. Schwenzfeier, A., Wierenga, P. A. \& Gruppen, H. Isolation and characterization of soluble protein from the green microalgae Tetraselmis sp. Biores. Tech. 102, 9121-9127 (2011).

14. Manahan, D. T. Adaptation by invertebrate larvae for nutrient acquisition from seawater. Am. Zool. 30, 147-160 (1990).

15. Sterner, R. W. \& Hessen, D. O. Algal nutrient limitation and the nutrition of aquatic herbivores. Annu. Rev. Ecol. Syst. 25, 1-29 (1994).

16. Hwang, P., Lee, T. H. \& Lin, L. Y. Ion regulation in fish gills: recent progress in the cellular and molecular mechanisms. Am. J. Physiol. Integr. Comput. Physiol. 301, R28-R47 (2011)

17. Skou, J. C. \& Esmann, M. The Na,K-ATPase. J. Bioenerg. Biomembr. 24, 249-261 (1992).

18. Manahan, D. T., Davis, J. P. \& Stephens, G. C. Bacteria-free sea urchin larvae: Selective uptake of neutral amino acids from seawater. Science 220, 204-206 (1983).

19. Davis, J. P., Keenan, C. L. \& Stephens, G. C. $\mathrm{Na}^{+}$-dependent amino acid transport in bacteria-free sea urchin larvae. J. Comput. Biochem. 156B, 121-127 (1985).
20. Leong, P. K. K. \& Manahan, D. T. Metabolic importance of $\mathrm{Na}^{+} / \mathrm{K}^{+}$ ATPase activity during sea urchin development. J. Exp. Biol. 200 2881-2892 (1997).

21. Stumpp, M., Dupont, S., Thorndyke, M. C. \& Melzner, F. $\mathrm{CO}_{2}$ induced acidification impacts sea urchin larval development II: Gene expression patterns in pluteus larvae. Comp. Biochem. Physiol. A 160, 320-330 (2011).

22. Bond, J. S. \& Butler, P. E. Intracellular proteases. Annu. Rev. Biochem. 56, 333-364 (1987)

23. Packard, B. Z. \& Komoriya, A. Intracellular protease activation in apoptosis and cell-mediated cytotoxicity characterized by cell-permeable fluorogenic protease substrates. Cell Res. 18, 238-247 (2008).

24. Burke, D. R. Structure of the digestive tract of pluteus larva of Dendraster excentricus (Echinodermata: Echinoidea). Zoomorph 98, 209-225 (1981).

25. Pfohl, R. J. Alkaline phosphatase of sea urchin embryos: Chromatographic and electrophoretic characterization. Dev. Biol. 44, 333-345 (1975).

26. Meyer, E. \& Mannahan, D. T. Nutrient uptake by marine invertebrates: cloning and functional analysis of amino acid transporter genes in developing sea urchins (Strongylocentrotus purpuratus). Biol. Bull. 217, 6-24 (2009).

27. Cruz-Rivera, E. \& Hay, M. E. Can quantity replace quality? Food choice, compensatory feeding, and fitness of marine mesograzers. Ecology 81, 201-219 (2000).

28. Slansky, F. Jr \& Wheeler, G. S. Caterpillars' compensatory feeding response to diluted nutrients leads to toxic allelochemical dose. Entomol. Exp. Appl. 65, 171-186 (1992)

29. Strathmann, R. R., Fenaux, L. \& Strathmann, M. F. Heterochronic developmental plasticity in larval sea urchins and its implications for evolution of nonfeeding larvae. Evolution 46, 972-986 (1992).

30. Ellis, D. A. A new universal buffer system. Nature 191, 1099-1100 (1961).

\section{Acknowledgements}

The authors are grateful to N. Dorey and E. Butera for their help with the larval culture. M.H. has received financial support from the European Community's Seventh Framework Programme FP7/2007-2013 under grant agreement no 265847 and an Alexander von Humboldt fellowship. M.S. was financially supported by the Royal Swedish Academy of Sciences (Kungliga Vetenskapsakademien). F.M. and M.B. were supported by the Excellence Cluster Future Ocean and the German Ocean Acidification programme BIOACID. I.C. and S.D. were financially supported by the Linnaeus Centre for Marine Evolutionary Biology at the University of Gothenburg (http://www.cemeb.science.gu.se/) and supported by a Linnaeus grant from the Swedish Research Councils VR and Formas.

\section{Author contributions}

M.S., M.H. and S.D. designed the study, conducted experiments, analysed the data and compiled the manuscript with the help of all other co-authors. R.S. contributed to enzyme characterizations. I.C. collected samples and performed the culture experiments including seawater chemistry analyses. M.B. and F.M. supported the planning operations for micro-electrode measurements and larval cultures.

\section{Additional information}

Supplementary information is available in the online version of the paper. Reprints and permissions information is available online at www.nature.com/reprints. Correspondence and requests for materials should be addressed to S.D.

\section{Competing financial interests}

The authors declare no competing financial interests. 